\title{
The Impact of Work-related Identity Discrepancy of Circle Members on Job Engagement: The Role of Negative Emotions ${ }^{1}$
}

\author{
Chang-e Liu \\ Wei Xie \\ Qian Wu Chenhong Hu Dan Liang \\ School of Business \\ Mobile E-business Collaborative Innovation Center of Hunan Province \\ Key Laboratory of Hunan Province for Mobile Business Intelligence \\ Hunan University of Technology and Business \\ Changsha China
}

\begin{abstract}
Circles are a kind of informal organization widely existing in human society. The current research on circles focuses more on the benefits brought by circle identity to members, and less on the loss of circle membership in the workplace, as the insider's work-related identity discrepancy due to the change of leadership. In the current research, based on affective event theory, we examined the extent to which negative emotions mediates the relationship between workrelated identity discrepancy and job engagement. With data collected from 578 employees in China, it showed that work-related identity discrepancy is associated with job engagement. Moreover, we found that negative emotions mediate the main effect. Implications for theory and practice are discussed.
\end{abstract}

Keywords: Work-related identity discrepancy, Negative Emotions, Job Engagement

\section{Introduction}

With the increasing pressure of competition among enterprises, it is urgent to stimulate the enthusiasm and initiative of employees to create more competitive advantages. Job Engagement is the mental state characterized by energy (positive and enthusiastic work motivation), dedication (identify with the work they are engaged in) and absorption (devote themselves to the work) (Schaufeli et al.,2002). Employees with high job engagement can not only improve their working ability and efficiency (Airila et al.,2012;Gilbert,2011), but also significantly improve the overall performance, profit margin, organizational citizenship behavior and customer satisfaction (Salanova et al.,2005;Xanthopoulou et al.,2009; Hu\&Wang.,2014;Halbesleben et al.,2009). However, there were a majority of studies showing that low job engagement had negative impact on employee mental health, and ultimately resulted in depression (Britt et al.,2005;Hakanen \& Schaufeli 2012).Therefore, it is necessary to discover more antecedents of job engagement and eliminate the negative effect.

Although the factors explaining employees' low job engagement remain relatively unclear, work-related identity has been identified as potentially playing a key role (Wright,1990;Britt,2003). Several studies have found work-related identity are closely related to employees' job engagement. Collecting 1208 American male soldiers' data, Britt (2003) found that when the work situation is unclear, work-related identity can predict the level of job engagement. Deng et al. (2014) points out there is a negative relationship between perceived identity discrepancy and employees' job engagement. By contrast, job characteristics and organizational support have significant positive on job engagement. (Saks, 2006). Different from the western countries, there are some informal groups in Chinese enterprises, which are called "circles". It widely exists in the organizations. The circle is a small, relatively closed, informal group (Liang, 1998). According to emotions and interests of members' exchange quality, dividing employees into "insiders" and "outsiders." Insiders can get more resources from the leaders when the leaders left, employees feel their identities are threatened, and then work-related identity discrepancy means that external events break the cognitive balance of existing work identity, resulting in a gap between the actual self and the ideal or ought self(Swann et al.,2009).

\footnotetext{
${ }^{1}$ This study was funded by a research grant from the NSFC (71672056; 71472062), and supported by Hunan Provincial Innovation Foundation for Postgraduate (CX2018B756).
} 
Previous studies have shown that work-related identity discrepancy can cause adverse consequences, such as increasing anxiety and stress, decreasing physical and mental health(Barreto\&Ellemers,2003;Barreto et al.,2010), causing interpersonal tension(Roberts,2005; Vough et al.,2013), confusion, self-doubt, and uncertainty, affecting creativity, increasing turnover rate, and reducing performance and job satisfaction(Polzer,Milton\&Swann,2002; Thatcher\&Greer,2008). In China, the relationship with the leader is more important than other countries. The departure of the leader means that the employees may change from "insiders" to "outsiders", then the resources and support they have will be correspondingly reduced. Compared with western countries, employees in China are more likely to generate work-related identity discrepancy after their leaders leave. Therefore, it's very important to explore the relationship between work-related identity discrepancy and employees' job engagement. Bledow et al. (2011) found that positive emotions had a positive effect on the individual job engagement. A study of 59 university employees in the Netherlands shows that at the daily level, positive emotional experience can predict three dimensions of job engagement (energy, dedication and absorption)(Ouweneel et al.,2012). In China, due to circle culture ,the relationship between employees and their superiors is closer than that in western countries. Therefore, when the supervisor is changed, subordinate's work-related identity discrepancy is more obvious. Self-discrepancy theory pointed out that negative discrepancy of ideal self-identity is related to depression, frustration, shame, and the discrepancy of negative ideal self-identity will produce anxiety emotions, such as anger and guilt (Higgins et al.,1997; Shah \& Higgins,2001). It's worthy to examine the extent to which negative emotions mediates the relationship between work-related identity discrepancy and job engagement.

Based on affective event theory, this study will examine the relationship between work-related identity discrepancy and job engagement, and the extent to which negative emotions mediates this relationship. It enriches the literature on work-related identity discrepancy on one hand and Chinese culture on the other hand. It also provides some suggestions to increase employee job engagement for management practice.

\section{Literature Review and Hypotheses}

\subsection{Perceived work-related identity discrepancy and job engagement}

Kahn (1990) concluded that the two conditions, including incentives or benefits and work with security, are necessary for job engagement. Employee can get a corresponding return and their identity or status will not be threatened. Current studies show that identity uncertainty is negatively correlated with job engagement. Britt (2003)confirmed that identity discrepancy damages self-esteem and reduces work passion; Wright(1990) showed that when employees believe they are in an unfair environment, they exhibit a range of defiant behavior (such as reducing work passion and decreasing job engagement);Deng(2014) pointed out that perceived identity discrepancy has a negative effect on job engagement. Work-related identity discrepancy is one kind of identity discrepancy, which is more common in organizations and closely related to employees' work. Hence, We speculate that work-related identity discrepancy has a negative impact on employees' job engagement.

Emotional event theory (EVT) was put forward by Weiss and Cropanzano in 1996, it shows that employees' experience of external events will affect individual emotions, and emotional reactions will affect individual actions and performances. Besides, EVT believes that employees' work behaviors are affected by work events. After the change of leader, employees' work-related identity discrepancy formed, which is an unexpected work event and breaks the balance between cognition and psychology of employees. Uncertainty about identities and worries about future jobs all have an impact on employees' work status, they can't concentrate on their work, then their job engagement reduced. Therefore, we predict that:

Hypothesis 1:Work-related identity discrepancy will have a negative effect on job engagement.

\subsection{The mediating effect of negative emotions}

Emotion is a psychological state generated by cognitive evaluation results of an event in a certain environment (Bagozzi et al.,1999), reflecting individuals' subjective cognition towards the work event. Negative emotions refer to a general state of subjective distress and unpleasurable engagement that subsumes a variety of aversive mood states, including anger, contempt, disgust, guilt, fear, and nervousness(Watson, Clark, \&Tellegen, 1988). It will narrow an individual's cognitive horizon, destroy and disintegrate the resources owned by the individual. When the individual is under control of negative emotions, his or her thinking and vision will be fixed in the negative situation, revealing such emotions as tension, anxiety and vigilance, and showing corresponding behavior, hindering his normal work(Fredrickson,2004;Yang et al.,2007). Bledow et al.(2011) showed that negative emotions will reduce employee job satisfaction and then lead to decreasing job engagement. Ouweneel et al(2012) pointed out that the individual's negative emotional experience directly affects the three dimensions of job involvement, namely energy, dedication and absorption. 
According to the emotional event theory, employees' experience of external events will affect individual emotions, and emotional reactions will affect individual actions and performances. The whole reaction processes form a state that events affect emotions, and emotions affect individual actions or performances. Leadership change as an external event, makes employees generate work-related identity discrepancy and then produces depression and anxiety, which will reduce employee psychological security and lead to tension, anxiety, in turn lead to the reduction of employees' job engagement. Therefore, we predict that:

Hypothesis 2: Negative Emotions will mediate the effect of work-related identity discrepancy on job engagement.

\section{Research Design}

\subsection{Participants and Procedure}

We distributed 835 copies of the survey from the employees of six private companies in Hunan and Guangdong province of China; 578 valid responses were collected, giving a response rate of $69.2 \%$. Of the valid respondents, $41.2 \%$ were men and $58.8 \%$ women. The average age of the respondents was 30.27 years $(\mathrm{SD}=5.06)$, ranging from 19 to 43 years. In terms of education, $8.7 \%$ of the respondents had a master's degree or above, $55.5 \%$ a bachelor's degree, and $35.8 \%$ had a high school diploma or below. Of the respondents $53.1 \%$ were employees, $24.2 \%$ supervisors, and $22.7 \%$ middle-level managers.

\subsection{Measures}

In order to ensure the reliability of measurement tools, we used the mature scales which other researchers have developed. All scales were scored by Likert 5 points ( $1=$ "strongly disagree"; $5=$ "strongly agree"). All scales in this study are described as following:

(1) Work-related identity discrepancy (WID) : At present, the scale of work-related identity discrepancy has not been developed. Therefore, this study developed an 7-item scale based on the Chinese situation and expert suggestions. Sample items include "I'm worried that I won't get along with the new leader." and so on. The scale's reliability was 0.875 .

(2) Job Engagement (JE) : We used job engagement scale by Schaufeli (2006) to assess job engagement, which contains 9-items. Among them, the first three items are "energy", the middle three are "dedication", and the last three are "absorption". Sample items include "When I work, I feel full of energy." and so on. The scale's reliability was 0.918 .

(3) Negative Emotions (NE) : We used negative emotions scale(PANAS) by Watson (1998) to assess negative emotions, which contains 8-items. Sample items include "I'm always ashamed." and so on. The scale's reliability was 0.921 .

(4) Control Variables: We controlled for respondents' demographic variables, including age, gender, education, tenure and occupation in the organization. As previous research suggested that these variables affect employees' behavior (Thau et al., 2009).To ensure the accuracy of the results, these variables are controlled.

\section{Results}

This study uses SPSS21.0 and AMOS17.0 to analyze the data. The steps are as follows: first, doing the descriptive statistical analysis of the data; second, testing the common method bias variation, and analyzing the data problems; third, it analyzes the direct effect and the moderating effect of the negative emotions.

\subsection{Descriptive statistics and correlation analysis}

The correlation coefficient, mean and standard deviation of the variables in this study are shown in table 1 . Workrelated identity discrepancy and job engagement showed strong negative correlation $(\gamma=-0.314, \mathrm{P}<0.01)$, and workrelated identity discrepancy and negative emotions have a strong positive correlation $(\gamma=0.589, \mathrm{P}<0.01)$, negative emotions and job engagement have significant negative correlation $(\gamma=-0.302, \mathrm{P}<0.01)$, The above data results preliminarily support the hypothesis of main effect and mediating effect in this study. 
Table 1 Means, Standard Deviations, and Correlations Among Study Variables

\begin{tabular}{|c|c|c|c|c|c|c|c|c|c|}
\hline Variable & $\bar{M}$ & SD & 1 & 2 & 3 & 4 & 5 & 6 & 7 \\
\hline 1.gender & 1.592 & .4919 & & & & & & & \\
\hline 2.marital status & 1.465 & .5670 & -.062 & & & & & & \\
\hline 3.education & 3.455 & .8750 & -.031 & $.270^{* * *}$ & & & & & \\
\hline 4.position & 3.273 & .8857 & $.304^{* * 4}$ & $-.269^{* * *}$ & $.190^{* *}$ & & & & \\
\hline $\begin{array}{l}\text { 5.Relationship with } \\
\text { ex-leader }\end{array}$ & 1.958 & .6770 & $.160^{* *}$ & -.073 & .019 & $.200^{* *}$ & & & \\
\hline 6.WID & 2.5167 & .80022 & .078 & $-.105^{*}$ & $-.102^{*}$ & .062 & .063 & & \\
\hline 7.NE & 2.0078 & .75109 & .081 & -.063 & $-.107^{*}$ & -.022 & .014 & $.589^{* * *}$ & \\
\hline 8.JE & 3.1940 & .87096 & -.032 & $.200^{* * 4}$ & .005 & $-.153^{\text {s.7 }}$ & $-.121^{5 * \pi}$ & $-.314^{* * 7}$ & $-.302^{x+1}$ \\
\hline
\end{tabular}

Note.WID=work-related identity discrepancy, NE=negative emotions, JE=job engagement

$* * * \mathrm{p}<0.001 ; * * \mathrm{p}<0.01 ; * \mathrm{p}<0.05$

\subsection{Common method bias}

Following H. Zhou and Long's (2004) suggestions, we first conducted varimax rotation analysis of principal factors for all variables to determine the presence and magnitude of common method variance, according to the number of factor precipitation or common factor interpretation. Four common factors (eigenvalue $>1$ ) were extracted from the test results, and the first factor explained only $39.687 \%$ of the variance, that is, less than the recommended explanation criterion of $50 \%$. Thus we reasonably concluded that common method variance in the present research was not significant.

\subsection{Reliability and validity analysis}

The study uses SPSS21.0 statistical analysis software to analyze the reliability and validity of scales. The results are shown in table 2. Cronbach alpha coefficients of all scales were above 0.80 , indicating that the reliability of the scale is quite high. The KMO values of each scale were all greater than 0.60 , and the results of Bartlett spherical test were significant, and each scale cumulative variances were greater than $50 \%$, indicating good validity.

Table 2 Reliability and Validity Analysis

\begin{tabular}{llll}
\hline Variable & Cronbach's Alpha & KMO & Cumulative Interpretation Variance \\
\hline WID & 0.875 & 0.847 & $72.88 \%$ \\
NE & 0.919 & 0.914 & $64.22 \%$ \\
JE & 0.960 & 0.959 & $75.96 \%$ \\
\hline
\end{tabular}

Note.WID=work-related identity discrepancy, NE=negative emotions, JE=job engagement

$* * * \mathrm{p}<0.001 ; * * \mathrm{p}<0.01 ; * \mathrm{p}<0.05$

In this study, AMOS21.0 software was employed to carry out confirmatory factor analysis for the three latent variables of work-related identity discrepancy, negative emotions and job engagement. The results show that the three-factor model assumed in this study has reached the acceptance criteria $(\mathrm{X} 2 / \mathrm{df}=2.78<5$, RMSEA $=0.078<0.08$, IFI, TLI, CFI are greater than 0.9). The results show that three variables have discriminant validity.

Table 3 Confirmatory Factor Analyses

\begin{tabular}{lllllll}
\hline Model & Factor & X2/df & RMSEA & IFI & TLI & CFI \\
\hline 1 & three-factor model & 2.78 & .078 & .922 & .906 & .920 \\
\hline 2 & two-factor model 1 & 3.62 & .093 & .875 & .853 & .868 \\
\hline 3 & two-factor model 2 & 4.25 & .149 & .774 & .741 & .773 \\
\hline 4 & two-factor model 3 & 5.89 & .180 & .667 & .619 & .678 \\
\hline 5 & one-factor model & 6.01 & .194 & .554 & .494 & .546 \\
\hline
\end{tabular}

\subsection{Hypothesis testing}

\section{Main effect test.}

This study uses the method of hierarchical regression analysis to verify the hypothesis, as shown in Table 4, the gender, marital status, education, position and as a control variable into the regression model. Then, the stepwise entry method is used to put the work-related identity discrepancy into the regression model. As shown in Table 4, the work-related 
identity discrepancy was negatively correlated with job engagement significantly $(\beta=-0.296, P<0.001$,M2). Thus, Hypothesis 1 is supported.

Table 4 The Main and Mediating Effects

\begin{tabular}{|c|c|c|c|c|c|c|c|}
\hline \multirow{2}{*}{\multicolumn{2}{|c|}{ Type of the Variable }} & \multicolumn{2}{|c|}{ Job Engagement } & \multirow[b]{2}{*}{ M3 } & \multirow[b]{2}{*}{ M4 } & \multicolumn{2}{|c|}{ Negative Emotions } \\
\hline & & M1 & M2 & & & M5 & M6 \\
\hline \multirow{5}{*}{$\begin{array}{l}\text { Control } \\
\text { variable }\end{array}$} & gender & 0.02 & 0.035 & 0.047 & 0.047 & 0.089 & 0.058 \\
\hline & marital status & .177 & .158 & $.156^{* * *}$ & $.162^{* * *}$ & -0.048 & -0.01 \\
\hline & education & -0.023 & -0.05 & -0.056 & -0.048 & -0.083 & -0.03 \\
\hline & position & -0.089 & -0.078 & $-.091^{*}$ & $-.103^{*}$ & -0.048 & -0.069 \\
\hline & $\begin{array}{l}\text { Relationship } \\
\text { ex-leader }\end{array}$ & with $-.093^{*}$ & -0.079 & $-.083^{*}$ & $-.090^{*}$ & 0.007 & -0.019 \\
\hline Independent & WID & & $-.296^{* * *}$ & $-.181^{* * *}$ & & & $.586^{* * *}$ \\
\hline mediator & $\mathrm{NE}$ & & & $-.196^{* * *}$ & $-.301^{* * *}$ & & \\
\hline$F$ & & 6.573 & 14.637 & 15.101 & 15.082 & 2.162 & 47.71 \\
\hline$R^{2}$ & & $.050^{* * * *}$ & $.135^{* * *}$ & $.158^{* * *}$ & $.138^{* * * *}$ & 0.011 & $.348^{* * *}$ \\
\hline$\Delta R^{2}$ & & 0.059 & 0.085 & 0.025 & 0.089 & 0.02 & 0.335 \\
\hline
\end{tabular}

Note.WID=work-related identity discrepancy, NE=negative emotions, JE=job engagement

$* * * \mathrm{p}<0.001 ; * * \mathrm{p}<0.01 ; * \mathrm{p}<0.05$

The mediating role of negative emotions.

According Baron and Kenny (1986), a mediating effect must meet three conditions: 1) The independent variable is associated with the dependent variable and the mediator; 2) the mediator has a significant effect on the dependent variable; and 3) when the independent variable and the mediator are simultaneously substituted into the regression equation to explain the dependent variable, the effect of the mediating variable is significant and the effect of the independent variable disappears (the fully mediating effect) or weakens (partial mediating effect).

As shown in Table 4, Work-related identity discrepancy is positively correlated with negative emotions $(\beta=.586, \mathrm{P}<$ .001 , M6), negatively correlated with job engagement $(\beta=-.296, p<0.001$, M2). Meanwhile, negative emotions is negatively correlated with job engagement $(\beta=-.196, p<0.001$, M3). Finally, when Work-related identity discrepancy and negative emotions were simultaneously entered into the regression equation, the negative effect of Work-related identity discrepancy is still significant $(\beta=-.301, \mathrm{p}<0.001, \mathrm{M} 4)$, but is weakened in comparison with M2 $(\beta=-.296, \mathrm{P}<$ $.001)$. These results reveal that negative emotions plays a partial mediating role between work-related identity discrepancy and job engagement. Therefore, hypothesis 2 is supported.

Table 5Bootstrap test for mediation effect

\begin{tabular}{lllll}
\hline Mediator & \multicolumn{4}{l}{ WID $(\mathrm{X}) \rightarrow \mathrm{NE}(\mathrm{M}) \rightarrow \mathrm{JE}(\mathrm{Y})$} \\
\cline { 2 - 5 } Negative emotions & effect & SE & LLCI & ULCI \\
\hline direct effect & -.2277 & .0552 & -.3362 & -.1192 \\
indirect effect & -.1143 & .0324 & -.1805 & -.0552 \\
\hline
\end{tabular}

We tested Hypothesis 2 with Hayes' (2013) PROCESS macro, in which 5,000 bias-corrected bootstrapped samples are used. the results shown in table 5.The indirect effect and 95\%confidence interval (CI) of work-related identity discrepancy on job engagement through negative emotions is -.1143, CI [-.1805, -.0552],not include 0. Hypothesis 2 is therefore supported.

\section{Discussion}

This paper mainly focuses on the effect of work-related identity discrepancy on job engagement, especially on the mediator role of negative emotions. It shows that:(1)work-related identity discrepancy significantly has a negative effect on job engagement;(2)negative emotions mediates the the relationship between work-related identity discrepancy and job engagement.

\subsection{Theoretical implications}


Our research mainly contributes to literature in two aspects. First, based on the affective event theory, we explore the relationship between work-related identity discrepancy and job engagement. Most scholars focus on positive antecedents on job engagement, but there is few research to employ perceived work-related identity discrepancy as the antecedent of employee job engagement. Meanwhile, as a psychological variable, work-related identity discrepancy was introduced into management research for the first time, which enriched the nomological network of identity research.

Second, this study suggests that negative emotions mediates the relationship between work-related identity discrepancy and job engagement. Chinese society always emphasized relationships, so when the leader leaves, work-related identity discrepancy may be more intense, which will make employees generate negative emotions and then reduce their job engagement. Meanwhile, it is of great significance to a full-scale understanding of the individual attitude and behavior changes in workplace.

\subsection{Management implications}

The results of this study show that work-related identity discrepancy has an obvious negative effect on job engagement. Therefore, the organization should pay more attention to the mental state of employees. Based on the above conclusions, we provide the following suggestions for organization managers. Firstly, the organization can establish a perfect company management system to ensure that employees enjoy the same treatment and have the same level of working resources as far as possible, so as to ensure that employees do not have a big work-related identity discrepancy due to the discrepancy in working resources. At the same time, we also point out that negative emotions mediates the relationship between work-related identity discrepancy and job engagement. Therefore, it is necessary to establish emotional venting mechanisms and build a harmonious organizational atmosphere to help employees properly digest negative emotions. Besides, at the individual level, employees should actively deal with emergencies, adjust their state of mind, and enhance the self-control of emotions. When there are too many negative emotions, employees can relieve the pressure in some ways(eg, chatting with friends, doing some sports, having a rest), so that they can recover more quickly and work hard.

\subsection{Limitations and directions for future research}

Although our research has contributed significantly to the theory and practice of managing perceived work-related identity discrepancy and job engagement, it comes with limitations. Firstly, we only collect the cross-sectional data and ignore the impact of time effects on variables, which makes it difficult to test the dynamic impact of work-related identity discrepancy on job engagement. But our hypothesis model have been confirmed, namely the work-related identity can be used as a predictor of job engagement. The conclusion is consistent with the findings of negative identity discrepancy in organizations (Higgins et al.,1997).The future researchers can use longtitudinal design, and through empirical sampling or field test method to collect horizontal and vertical data, which will make it more accurately to grasp the relationship among variables; Second, it uses the single-source data measurement methods and the conclusions will be influenced easily by common method variance. In this study, employee self-evaluation is used to obtain employee job engagement data. However, employees are likely to consider their own face problems and have reservations in filling in questionnaire. Therefore, other evaluation ways are more likely to restore the essence of job engagement. In order to reduce measurement deviation, the suggestions of Podsakoff can be taken. Through protecting the privacy of interviewees, the concern to employees ev evaluation will be lower. At the same time, confirmatory factor analysis was conducted on the data, and the results showed that there was a good distinction between the main variables. Therefore, future research can use multi-source or other assessment methods to obtain data to avoid the impact of homologous error.

\section{References}

Airila ,A., Hakanen,J., Punakallio, A., et al.(2012). Is work engagement related to work ability beyond working conditions and lifestyle factors?. International Archives of Occupational 6Ashforth, B. E., \& Mael, F. A.(2001). Identification in Work, War, Sports, and Religion: Contrasting the Benefits and Risks. Journal for the Theory of Social Behavior, 31(2): 197-222.

Bagozzi, R. P., Gopinath, M., \&Nyer, P .U.(1999). The role of emotions in marketing. Journal of the Academy of Marketing Science, 27(2):184.

Barreto, M., Ellemers, N., Scholten, W., \& Smith, H.(2010). To Be or Not To Be: The Impact of Implicit Versus Explicit Inappropriate Social Categorizations on the Self. British Journal of Social Psychology, 49(1): 43-67.

Barreto, M., \& Ellemers, N. (2003). The effects of being categorised: The interplay between internal and external social identities. European Review of Social Psychology, 14(1): 139-170. 
Bledow, R., Schmitt, A., Frese, M., \& Kühnel, J. (2011). The Affective Shift Model of Work Engagement. Journal of Applied Psychology, 96(6):1246-1257.

Bonanno, G. A.(2004). Loss, Trauma, and Human Resilience: Have We Underestimated the Human Capacity to Thrive after Extremely Aversive Events?.American Psychologist, 59(1):20-28.

Chen, W. Z., Li, J. P.,\& Wu, J. H.(2006). Research On the Influence of Organizational Climate on Employees' Work Engagement and Organizational Commitment. Management Science, 19(6):18-23.

Conroy, S. A. \& O'Leary-Kelly, A. M.(2014). Letting Go and Moving On: Work-Related Identity Loss and Recovery. Academy of Management Review, 39(1): 67-87.

Dansereau, Jr, F., Cashman, J., \& Graen, G. (1973). Instrumentality Theory and Equity Theory as Complementary Approaches in predicting the Relationship and Turnover Among Managers. Organizational Behavior and Human Performance, 10(2): 184-200.

Dutton, J., Roberts, L. M., \& Bednar, J. (2010). Pathways for Positive Identity Construction at Work: Four Types of Positive Identity and the Building of Social Resources. Academy of Management Review, 35(2): 265-293.

Ebaugh, H. R. F. (1988). Becoming an EX : The process of role exit. Chicago : University of Chicago Press.

Fredrickson, B. L.(2004). The role of Positive Emotions in Positive Psychology : The Broaden and Build Theory of Positive Emotions. American Psychologist, 359(1449): 1367-1377.

Gecas, V. (1982). The Self-Concept. Annual Review of Sociology, 8(8): 1-33.

Gilbert J.(2011).The millennial: a new generation of employees, a new set of engagement policies.Ivey Business Journal, 75(5):26-28.

Halbesleben, J.R.B., Harvey, J., Bolino, M. C.(2009). Too engaged? A conservation of resources view of the relationship between work engagement and work interference with family. Journal of Applied Psychology, 94(6):1452-1465.

Higgins, E. T.(1987). Self-Discrepancy: A theory Relating Self and Affect. Psychological Review, 94(3): 319-340.

Hu, S. N., Wang, Y. (2014). Concept, Measurement, Antecessor and Aftereffect of Job Involvement. Advances in Psychological Science, 22(12):1975-1984.

Ibarra, H. (1999). Provisional Selves: Experimenting with Image and Identity in Professional Adaptation. Administrative Science Quarterly, 44(4):764-791.

Ibarra, H., \& Barbulescu, R. (2010). Identity as Narrative: Prevalence, Effectiveness, and Consequences of Narrative. Academy of Management Review, 35(1): 135-154.

Izard, C. E. (1977). Human emotions, New York

Ji, N, L. (2017). Three Psychological Attributes of Chinese Circles, Journal of Jinan University (Social Science Edition), 27(03):28-30.

Jin, J., Hu, J. S. (2015). Suppression of Dominant Cognitive Processing by Negative Emotions. Advances in Psychological Science,23(1):61-71.

Kahn, W. A. (1990). Psychological Conditions of Personal Engagement and Disengagement at Work. Academy of Management Journal, 3(4): 692-724.

Maslach, C., Schaufeli, W. B., \&Leiter, M.P.(2001). Job Burnout. Annual Review of Psychology, 52(1):397-422.

May, D. R., Gilson, R. L., \& Harter, L. M. (2004).The psychological conditions of meaningfulness, safety and availability and the engagement of the human spirit at work. Journal of Occupational \& Organizational Psychology, 77(1), 11-37.

Li, F. X. (2010). Emotional Motivation - Differentiation Theory and its Application in Emotional Regulation. Social Psychological Science, (7):90-92.

Liang, J. P. (1998). "Circle Culture" in Enterprise Organization -- A Hypothesis About Organizational Culture. Economic Science, 37(5):13-18.

Luo, J. D. (2013). Circle Phenomenon in Business. China's Human Resources Development, 37(2): 106-108.

Lazarus, H. (1970). Book Review: Organizational Behavior: Supervision: Situation,Individual, Behavior, Effect. Industrial\&Labor Relations Review, 23(4): 623-625.

Ouweneel, E., Le Blanc, P. M., Schaufeli, W. B., \& Van Wijhe, C. I.(2012). Good Morning, Good Day: A Diarystudy on Positive Emotions, Hope, and Work Engagement. Human Relations, 65(9):1129-1154.

Perry, J. T. (1994). The Role of Subordinate Performance and Ingratiation in Leader-member Exchanges. Group \& Organization Management, 19(1): 67-86.

Polzer, J. T., Milton, L. P., \& Swann, W. B., Jr. (2002). Capitalizing on diversity: Interpersonal congruence in small work groups. Administrative Science Quarterly, 47(2): 296-324.

Roberts, L. M.(2005). Changing faces: Professional image construction in diverse organizational settings. Academy of Management Review, 30(4): 685-711. 
Salanova M , Agut S , Peiró, José María.(2005). Linking Organizational Resources and Work Engagement to Employee Performance and Customer Loyalty: The Mediation of Service Climate. Journal of Applied Psychology,90(6):1217-1227.

Schaufeli, W. B., Salanova M., \&Gonzalez- Roma V., et al. (2002). The Measurement of Engagement and Burnout: A Two Sample Confirmatory Factor Analytic Approach. Journal of Happiness Studies, 3(1): 71-92.

Shah, J., \& Higgins, E. T. (2001). Regulatory Concerns and Appraisal Efficiency: The General Impact of Promotion and Prevention. Journal of Personality and Social Psychology, 80(5): 693-705.

Swarm, W. B., Johnson R. E., \&Bosson J. K.(2009). Identity Negotiation at Work. Research in Organizational Behavior, 29:81-109.

Sveningsson, S. F., \& Alvesson, M. (2003). Managing Managerial Identities: Organizational Fragmentation, Discourse and Identity Struggle.Human Relations, 56(10):1163-1193

Thatcher, S. M. B., \& Green, L. L. (2008) . Does It Really Matter If You Recognize Who I am? The Implications of Identity Comprehension for Individuals in Work Teams. Journal of Management,4(2): 5-24.

Tian, X, Z., Dong, Q., \& Ma, K. (2016). A Review of Research on Work Identity Transformation. Foreign Economy and Management, 38(08):81-94.

Vignoles, V. L., Regalia, C., \&Manzi C., et al. (2006). Beyond Self-Esteem: Influence of Multiple Motives on Identity Construction. Journal of Personality\&Social Psychology, 90(2):308-33.

Vough, H., Cardador, T., Bednar, J.,Dane, E., \& Pratt, M.(2013). What Clients don't get about My Profession: A Model of Perceived Role-Based Image Discrepancies. Academy of Management Journal, 56(4): 1050-1080.

Wang, W. K. (2003). Perspective of the Circle Phenomenon in Modern Administrative Organizations. Journal of Yunan University of Administration, 18(5):15-17.

Watson D , Clark L A, Tellegen A .(1988). Development and validation of brief measures of positive and negative affect: The PANAS scales. Journal of Personality and Social Psychology, 54(6):1063-1070.

Weiss, H. M., Cropanzano, R. (1996). Affective Events Theory: A Theoretical Discussion of the Structure, Causes and Consequences of Affective Experiences at Work. Research in Organizational Behavior, 18(3), 1-74.

Xanthopoulou D , Bakker A B , Demerouti E, et al.(2009). Work engagement and financial returns: A diary study on the role of job and personal resources. Journal of Occupational and Organizational Psychology, 82(1):183-200.

Xu, H, L., \& Liang, J, P. (2007). Explore the Inner Circle Phenomenon of the Organization, China's Human Resources Development, 31(12):36-39.

Yang, L. Z., Dong, G. H, \& Jing, X. L. (2007). A Review of the Brain Response Differences Between Positive and Negative Emotions. Psychological and Behavioral Research, (3):224-228.

Ying, J. (2018). Paternalistic Leadership and Employee Engagement: Mediating Role of workplace Status. East China Normal University,Shanghai. 